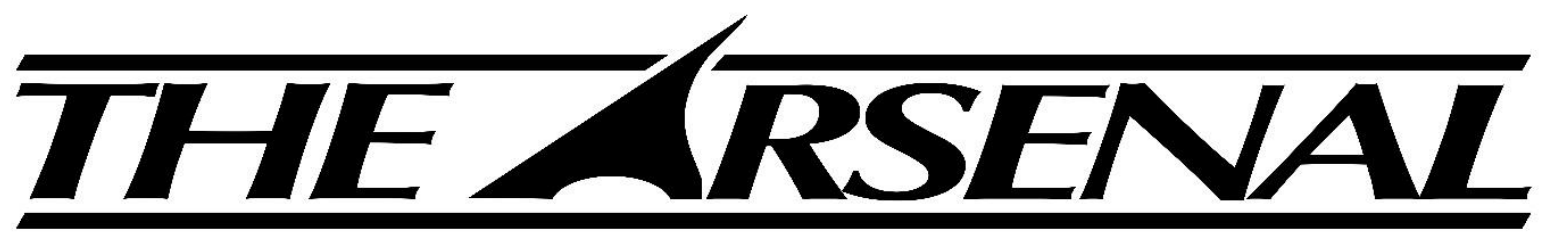

Augusta University's Undergraduate Research Journal

ISSN 2380-5064 | The Arsenal is published by the Augusta University Libraries | http://guides.augusta.edu/arsenal

Volume 4, Issue 1 (2021)

Special Edition Issue

\title{
ROUTINE USE OF NONSTEROIDAL ANTI-INFLAMMATORY DRUGS IS EFFECTIVE AND SAFE WHEN USED POSTOPERATIVELY IN PEDIATRIC PATIENTS
}

Nadine Long, Danielle Crethers, and Renuka Mehta

\section{Citation}

Long, N., Crethers, D., \& Mehta, R. (2021). Routine use of nonsteroidal anti-inflammatory drugs is effective and safe when used postoperatively in pediatric patients. The Arsenal: The Undergraduate Research Journal of Augusta University, 4(1), 23.

http://doi.org/10.21633/issn.2380.5064/s.2021.04.01.23

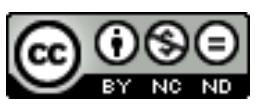

(C) Long, Crethers, and Mehta 2021. This open access article is distributed under a Creative Commons Attribution NonCommercial-NoDerivs 2.0 Generic License (https://creativecommons.org/licenses/by-nc-nd/2.0/). 


\section{Routine Use of Nonsteroidal Anti-Inflammatory Drugs is Effective and Safe When Used Postoperatively in Pediatric Patients}

Presenter(s): Nadine Long

Author(s): Nadine Long ${ }^{1}$, Danielle Crethers ${ }^{2}$, and Renuka Mehta ${ }^{3}$

Faculty Sponsor(s): Renuka Mehta, MBBS

Affiliation(s): ${ }^{1}$ College of Science and Mathematics, ${ }^{2}$ Department of Clinical \& Translational Sciences, ${ }^{3}$ Department of Pediatrics (Augusta Univ.)

\section{ABSTRACT}

Nonsteroidal anti-inflammatory drugs (NSAIDS) (i.e ibuprofen) are effective analgesic. Compared to other drugs like opioids (i.e., morphine), it can reduce the possibility of experiencing adverse side effects such as respiratory depression, nausea, and vomiting. However, though effective, NSAIDs have been known to potentially induce bleeding and renal dysfunction, which lead to concerns using them postoperatively. In this study, we sought to determine the effectiveness of NSAIDs, their related side effects compared to opioids, and evaluate the risk of bleeding complications and renal dysfunction in postoperative pediatric patients. This suggests that NSAIDs are equally effective as opioids in both the management of postoperative pain and the perception of treatment. However, opioids appear to induce more side effects than patients who were given NSAIDs postoperatively. Thus, making NSAIDs appears to be an effective and feasible alternate for post-operative pain management.

Received: 01/31/2020 Accepted: 02/17/2020

Correspondence: Nadine Long, Augusta University, $112015^{\text {th }}$ St. Augusta, GA 30912, nalong@ augusta.edu 